\title{
Surgeons' Attitudes About Use of Preoperative Risk Assessment Tools
}

\section{Nisha Pradhan}

University of Colorado School of Medicine

Adam R. Dyas

University of Colorado School of Medicine

Michael R. Bronsert

University of Colorado School of Medicine

Anne Lambert-Kerzner

University of Colorado School of Medicine

William G. Henderson

University of Colorado School of Medicine

Howe Qiu

University of Colorado School of Medicine

Kathryn L. Colborn

University of Colorado School of Medicine

Nicholas J. Mason

University of Colorado School of Medicine

Robert A. Meguid ( $\nabla$ robert.meguid@cuanschutz.edu)

University of Colorado School of Medicine

\section{Research Article}

Keywords: risk assessment, SURPAS, NSQIP, VASQIP

Posted Date: November 16th, 2021

DOI: https://doi.org/10.21203/rs.3.rs-1075088/v1

License: (c) (i) This work is licensed under a Creative Commons Attribution 4.0 International License.

Read Full License 


\section{Abstract}

Background: Formal surgical risk assessment tools have been developed to predict risk of adverse postoperative patient outcomes. Such tools accurately predict common postoperative complications, inform patients and providers of likely perioperative outcomes, guide decision making, and improve patient care. However, these are underutilized. We studied the attitudes towards and techniques of how surgeons preoperatively assess risk.

Methods: 108 surgical faculty, 95 surgical residents, and 58 affiliate surgeons at a large academic tertiary referral hospital and affiliate community hospitals were emailed a 16-question survey between 8/2019$6 / 2020$. Surveys were analyzed using descriptive statistics (frequency distributions and percentages for categorical variables, means, and standard deviations for continuous variables), and Fisher's exact test and unpaired t-tests comparing responses by surgical attendings vs. residents.

Results: Overall response rates were $50.0 \%$ for faculty surgeons, $47.4 \%$ for residents, and $36.2 \%$ for affiliate surgeons. Only $20.8 \%$ of surgeons used risk calculators most or all of the time. Attending surgeons were more likely to use prior experience and current literature while residents used risk calculators more frequently. Risk assessment tools were more likely to be used when predicting major complications and death in older patients with significant risk factors. Greatest barriers for use of risk assessment tools included time, inaccessibility, and trust in accuracy.

Conclusions: Even though risk assessment tools are available, few surgeons use them as part of their routine practices. Developers of the tools need to design the tools to better promote the positive features and to avoid the burdens commonly reported by users.

\section{Background}

Despite advances in surgical technique, understanding of surgical pathology and pathophysiology, and knowledge of factors that increase risk of adverse post-operative outcomes, accurate assessment of a patient's surgical risk preoperatively remains challenging. Although surgical risk assessment tools such as the American College of Surgeons' Surgical Risk Calculator,[1] the Veterans Affairs Surgical Quality Improvement Program (VASQIP) Patient Risk Calculation, and the Surgical Risk Preoperative Assessment System (SURPAS)[2] accurately predict risk of adverse postoperative patient outcomes, these tools have not been widely adopted by surgeons to routinely assess preoperative surgical risk[3, 4]. Surgeons are accurate at predicting preoperative risk in low-risk patients, but they are inaccurate when predicting risk of adverse events in high-risk patients.[2] This is problematic as high-risk patients are the most likely to benefit from pre-operative counseling, informed consent discussions, and potential risk mitigation efforts.

Implementation of formal preoperative risk assessment may optimize understanding of risk of adverse postoperative outcomes by both surgical teams and patients[3,4]. Patients desire to understand their risks, and report increased shared decision making with use of such tools[5-8]. The use of personalized risk assessment both increases the patient's understanding of the proposed operation and improves the 
communication of informed consent and individualized patient risks[9], which improves patient-centered care and shared decision making. Beyond improving the patient experience and patient perception of improved informed consent, surgeon use of such tools has been shown to lead to more accurate judgments of operative risk $[10,11]$. These tools have allowed the operative decision-making process to become more objective in evaluating for potential postoperative complications[12]. Therefore, increased understanding of barriers to use of risk assessment tools is warranted.

The purpose of this study was to collect information on surgeons' attitudes toward surgical risk tools, including how often they are used compared to other methods of risk assessment, how risk is communicated to patients, what factors increase the likelihood of using surgical risk tools, what are barriers to use of surgical risk tools, and which features enhance usefulness of surgical risk tools. It is also important to determine if level of training (e.g., resident physician vs. attending physician) impacts attitudes about surgical risk assessment. We hypothesized that: (1) a small percentage of surgeons routinely use preoperative risk assessment tools; (2) that attending surgeons are more likely to rely on prior experience to guide risk assessment, and residents are more likely to use surgical risk tools; and (3) that time is a significant barrier to use.

\section{Methods}

\section{Ethical Oversight}

This research was conducted after review and approval from the Colorado Multiple Institutional Review Board (COMIRB\#: 19-1068).

\section{Study Design and Selection Criteria}

This study was a prospective data collection using a survey developed by the research team under the guidance of a qualitative specialist with extensive experience in survey design (co-author ALK). The team designed a 16-question multiple choice survey to elicit opinions of and attitudes towards use of formalized risk assessment tools [Appendix 1]. Specifically, we used a series of multiple-choice questions that assessed the respondent's frequency of risk discussions with patients, methods used, time spent, the sources of the risk information, useful features of a risk assessment tool, and barriers to use. The survey was designed such that respondents could choose to remain anonymous.

The survey was administered to surgical faculty and residents in the Department of Surgery at the University of Colorado Hospital ( $\mathrm{UCH}$ ), the Rocky Mountain Regional Veterans Administration Medical Center, Children's Hospital of Colorado, Denver Health Hospital, and to affiliate appointments of the Department of Surgery in the years 2019-2020. Surgical faculty and residents included the surgical specialties of general, trauma/ acute care, surgical critical care, surgical oncology, vascular, cardiac, thoracic, plastic reconstructive, colorectal, transplant, endocrine and urology. Affiliates included academic-affiliate hospitals within the UCHealth system. Survey response was incentivized through two $\$ 50$ gift card raffles, one for surgical faculty and one for surgical residents. Reminder emails were sent 
once weekly for three weeks after the initial survey was disseminated. Surveys were disseminated and responses collected through REDCap (Research Electronic Data Capture, Vanderbilt University, Nashville, $\mathrm{TN})$, a software tool for designing and collecting data for a research database. In addition to the 16 survey questions, we also collected the following data about the surgeon responders: age, gender, years of practice, specialty, education, hospital type, and hospital bed size.

Statistical Analysis

Descriptive statistics, including frequency distributions and percentages for categorical variables, means, and standard deviations for continuous variables, were used to summarize the survey results. Group comparisons were performed using Fisher's exact test for categorical variables, and unpaired t-test or Wilcoxon rank sum test for continuous variables. Results were considered statistically significant for $\mathrm{p} \leq 0.05$. All statistical analysis was performed using SAS version 9.4 [SAS Inc, Cary, NC].

\section{Results}

A total of 261 surveys were emailed (108 to faculty surgeons, 95 to residents, and 58 to affiliated surgeons). One hundred twenty (46.0\%) were completed (54 faculty surgeons, 45 residents, 21 affiliate surgeons). Response rates were $50.0 \%$ for faculty surgeons, $47.4 \%$ for residents, and $36.2 \%$ for affiliate surgeons. Two additional surveys were received but excluded due to incomplete data or the surgeon no longer being in clinical practice.

Table 1 presents the demographic information of survey participants. Approximately $40 \%$ of residents and affiliated surgeons were female, but only $26 \%$ of faculty surgeons. Average age and median years of practice of faculty and affiliate surgeons were similar (49.6 and 10 years vs. 46.0 and 12 years, respectively). The 120 surgeons were from general surgery $(70.0 \%)$, urology $(7.5 \%)$, vascular $(6.7 \%)$, cardiac (3.3\%), and other specialties (12.5\%); and from an academic hospital (UCH) (78.3\%), urban community hospital $(15.8 \%)$, or rural hospital and other settings $(5.8 \%)$.

Table 2 presents the 120 respondents' practices for risk discussion with their patients. For comparisons, faculty and affiliate surgeons were combined and compared to residents. Among all 120 surgeons, 45.0\% spent 5-9 minutes discussing risk, and $36.6 \%$ took more than 10 minutes; $72.5 \%$ used prior experience (all percentages are most or all of the time, unless otherwise specified) and $60.0 \%$ used current literature as their sources of risk estimates, while only $20.8 \%$ used online risk calculators as a source of risk estimates. The primary methods that the surgeons used to communicate risk to patients included face to face (90.0\%) and pre-anesthesia clinic (51.6\%); phone calls (4.1\%), residents (19.2\%), advanced practice providers, (4.2\%), handouts/pamphlets (19.2\%), and classes/videos (6.6\%) were used much less frequently. Only $20.8 \%$ of the surgeons communicated risk back to the referring provider most or all of the time. Compared to the faculty and affiliate surgeons, residents spent less time discussing risk with patients $(20.0 \%$ vs. $46.7 \%>10$ minutes, $p=0.004)$, used risk calculators more often $(62.2 \%$ vs. $49.4 \%$ sometimes to always, $p=0.002)$, and prior experience $(62.2 \%$ vs. $78.6 \%, p<0.0001)$ and current literature ( $44.4 \%$ vs. $69.3 \%, p=0.004)$ less often as the sources of risk estimates. They also mainly used face to 
face to communicate risk to patients and used residents more often ( $46.6 \%$ vs. $2.7 \%, p<0.0001)$ and preanesthesia clinic ( $42.2 \%$ vs. $57.3 \%, p=0.02)$ and handouts/pamphlets $(4.4 \%$ vs. $28.0 \%, p<0.0001)$ less often compared to faculty and affiliate surgeons. They also communicated the risk less often to referring providers $(6.6 \%$ vs. $29.4 \%, p<0.001)$.

Table 3 presents factors related to when surgeons might be more likely to use risk assessment tools. Among all 120 surgeons, $90.0 \%$ were more likely to use risk assessment tools when patients had significant risk factors, $76.7 \%$ when patients were $>65$ years old, $70.0 \%$ to dissuade patients/families from surgery, $69.2 \%$ when patients asked about risks, and $49.2 \%$ when patients needed emergency operations. There were no statistically significant differences between faculty and affiliate surgeons and residents on these attitudes.

Table 4 presents respondents' attitudes towards barriers in using risk calculators and the utility of certain features of risk calculators. Among all respondents, $65.9 \%$ thought time was a moderate or significant barrier, $61.7 \%$ not being integrated into the electronic health record (EHR) or inaccessibility during patient visit, $59.2 \%$ trust in accuracy, $46.7 \%$ inability of patient to understand, and $32.5 \%$ patient language barrier. Compared to faculty and affiliate surgeons, residents thought that inaccessibility of the tool during the patient visit and native language of patient were more moderate or significant barriers. Among all 120 surgeons, $93.3 \%$ thought prediction of major complications and mortality made risk calculators very or extremely useful, $80.9 \%$ automatic integration of risk factors from the EHR, $80.0 \%$ prediction of postsurgery infection, $77.5 \%$ automatic recording of results into the EHR, $75.0 \%$ prediction of a good surgical outcome, and $48.3 \%$ prediction of minor complications. There were no statistically significant differences in attitudes toward features that make risk calculators useful between the faculty and residents.

We also examined surgeon attitudes toward risk discussions with patients and use of risk assessment tools between the 21 affiliate and the 54 faculty surgeons. The attitudes were similar for all questions, with the exceptions of use of residents to communicate risk and whether they were more likely to use risk assessment tools for emergent operations. Faculty used residents more to communicate risk ( $70 \%$ for faculty vs. $14 \%$ for affiliate surgeons rarely to always, $p<0.0001)$ and they were more likely to use risk assessment tools for emergent operations ( $63 \%$ vs. $38 \%, p=0.05)$. We also examined surgeon characteristics (gender, age, years of practice, education, type and bed size of facility practicing in) related to whether they used risk assessment tools never/rarely $(n=55)$, sometimes $(n=40)$, or most of the time/always $(n=25)$ (data not presented). We found no consistent trends between any of the surgeon characteristics and their use of risk assessment tools.

\section{Discussion}

This study found that a small percentage of surgeons (20.8\%) used on-line risk calculators most or all of the time; that attendings were more likely to use prior experience and current literature and residents more likely to use risk calculators as a source of risk estimates; and that time was the number one barrier to use of risk calculators. The surgeons were also more likely to use risk calculators when patients were 
older, had significant risk factors, to dissuade patients and families about surgery when risk was high, or when patients asked about risk. Risk calculators were thought to be more useful for prediction of major complications, mortality, and post-surgical infection; when they were built into the EHR, when they automatically recorded results into the EHR; and when they predicted a good surgical outcome; they were less useful for minor complications. Top barriers for use of risk calculators, in addition to time, were thought to be accessibility and not being in the EHR, trust, inability of patients to understand, and language barriers.

It is not surprising that residents would rely more on risk calculators and less on their prior experience in estimating preoperative risk. The average age of the residents was 30.7 years, so they might be more in tune with computer technology, and they had more limited prior clinical experience. The fact that the surgeons were more interested in risk prediction tools for older patients with more risk factors and to dissuade patients with very high risk agrees with our previous research which showed that surgeons thought a risk calculator was more useful for high-risk patients and less useful for low-risk patients[2, 4].

Meguid, et al,[13-17] have developed a surgical risk calculator that has some of the features thought to make a risk calculator useful and to avoid some of the perceived barriers. Called the Surgical Risk Preoperative Assessment System (SURPAS), the risk calculator covers 9 surgical specialties (general, gynecology, neurosurgery, orthopedics, otolaryngology, plastics, thoracic, urology, and vascular), only requires the input of 8 preoperative variables (4 related to the operation-CPT-specific event rate, work $\mathrm{RVU}$, inpatient/outpatient, and specialty; and 4 related to the patient-age, ASA class, functional health status, and emergency), and calculates a patient's risk for 12 postoperative adverse events (30-day mortality, overall morbidity, unplanned readmission, discharge not to home, and the 8 specific complications of infection, cardiac, pulmonary, renal, UTI, VTE, bleeding, and stroke). Thus, the calculator is easy to use, taking only a few minutes to input data (time barrier); covers the major postoperative complications; is built into the EHR at the UCHealth system; and writes a note into the patient's EHR record. Further, multiple validation studies have been done using internal[16-20] and external[21-24] validation methods, to address the issue of "trust" in the accuracy of the models. Several pilot studies have also been completed recently showing that after SURPAS patients understand their risks for surgery very well[2] and have improved satisfaction, comfort, and anxiety about their operations[9].

Other studies have shown that risk assessment tools are underutilized by trainees, favoring traditional models of communication due to lack of an electronic health record and clinical workflow interruption[25]. This remains true for attending surgeons as well. A patient's native language may also pose a barrier to using risk calculator tools in hospitals where interpreter services are not readily available. A formal handout given at the end of the visit, complete with visuals of risk, may help reinforce the preoperative risk discussion. When surgeons forego using a surgical risk calculator, they misestimate a patient's risk of postoperative adverse events regardless of level of training[10].

In order to successfully implement surgical risk tools, especially in a high-volume clinic setting, accessing and using these tools must be quick, seamless, and accurate. Both ACS-NSQIP and VASQIP 
require manual entry of over 20 pre-operative variables, including laboratory values that may not be readily available for all pre-operative patients. These factors might preclude widespread use in a large volume pre-operative clinic setting where surgeons may only have 15 minutes allotted for the entire patient encounter.

This study had two major limitations: (1) Respondents were from just one health system (UCHealth). However, the health system did have different types of hospitals, including a large university hospital, several community hospitals, and a few rural hospitals; and (2) The overall response rate was only $46.0 \%$. However, this was somewhat better than the typical response rates of $20-30 \%$ observed in other physician surveys[26].

\section{Conclusions}

Only twenty percent of the surveyed surgeons used a risk calculator most or all of the time. Attending surgeons were more likely to use prior experience and current literature as sources for risk information, while residents were more likely to use risk calculators. Time was cited as the most important barrier to use of a risk calculator.

\section{List Of Abbreviations}

- COMIRB: Colorado Multiple Institutional Review Board

- REDCap: Research Electronic Data Capture

- ACS-NSQIP: American College of Surgeons' Surgical Risk Calculator

- VASQIP: Veterans Affairs Surgical Quality Improvement Program

- UCH: University of Colorado Hospital

- SURPAS: Surgical Risk Preoperative Assessment System

\section{Declarations}

- Ethics approval and consent to participate: This research was conducted after review and approval from the Colorado Multiple Institutional Review Board (COMIRB\#: 19-1068).

- Consent for publication: Not applicable

- Availability of data and materials: The datasets used and/or analyzed during the current study are available from the corresponding author on reasonable request.

- Competing interests: The authors declare that they have no competing interests.

- Funding: Provided by the University of Colorado School of Medicine Mentored Scholarly Activities program.

- Authors' contributions: The conception and design of the study, or acquisition of data, or analysis and interpretation of data: NP, MRR, AL, WGH, HQ, RAM. The drafting of the article or revising it 
critically for important intellectual content: NP, ARD, WGH, KLC, RAM. The final approval of the version to be submitted: NP, ARD, MRR, AL, WGH, HQ, NJM, KLC, RAM.

- Acknowledgements: We would like to thank Dr. Karl Hammermeister for his expertise and assistance with study design and Dr. L. A. Crane for her help with the survey design.

\section{References}

1. Bilimoria KY, Liu Y, Paruch JL, Zhou L, Kmiecik TE, Ko CY, et al. Development and evaluation of the universal ACS NSQIP surgical risk calculator: a decision aid and informed consent tool for patients and surgeons. J Am Coll Surg. 2013;217(5):833-42 e1-3.

2. Bronsert MR, Lambert-Kerzner A, Henderson WG, Hammermeister KE, Atuanya $C$, Aasen DM, et al. The value of the "Surgical Risk Preoperative Assessment System" (SURPAS) in preoperative consultation for elective surgery: a pilot study. Patient Saf Surg. 2020;14:31.

3. Aasen DM, Wiesen BM, Singh AB, Piper C, Harnke B, Prochazka AV, et al. Systematic Review of Preoperative Risk Discussion in Practice. J Surg Educ. 2020;77(4):911-20.

4. Lambert-Kerzner A, Ford KL, Hammermeister KE, Henderson WG, Bronsert MR, Meguid RA. Assessment of attitudes towards future implementation of the "Surgical Risk Preoperative Assessment System" (SURPAS) tool: a pilot survey among patients, surgeons, and hospital administrators. Patient Saf Surg. 2018;12:12.

5. Kriwanek S, Armbruster C, Beckerhinn P, Blauensteier W, Gschwantler M. Patients' assessment and recall of surgical information after laparoscopic cholecystectomy. Dig Surg. 1998;15(6):669-73.

6. McGaughey I. Informed consent and knee arthroscopies: an evaluation of patient understanding and satisfaction. Knee. 2004;11(3):237-42.

7. Ochieng J, Buwembo W, Munabi I, Ibingira C, Kiryowa H, Nzarubara G, et al. Informed consent in clinical practice: patients' experiences and perspectives following surgery. BMC Res Notes. 2015;8:765.

8. Tuveri M, Caocci G, Efficace F, Medas F, Collins GS, Pisu S. Different perception of surgical risks between physicians and patients undergoing laparoscopic cholecystectomy. Surg Laparosc Endosc Percutan Tech. 2009;19(4):305-11.

9. Wiesen BM, Bronsert MR, Aasen DM, Singh AB, Lambert-Kerzner A, Henderson WG, et al. Use of Surgical Risk Preoperative Assessment System (SURPAS) and Patient Satisfaction During Informed Consent for Surgery. J Am Coll Surg. 2020;230(6):1025-33 e1.

10. Pei KY, Healy J, Davis KA. Surgeons overestimate postoperative complications and death when compared with the National Surgical Quality Improvement Project risk calculator. J Surg Res. 2018;225:95-100. 
11. Sacks GD, Dawes AJ, Ettner SL, Brook RH, Fox CR, Russell MM, et al. Impact of a Risk Calculator on Risk Perception and Surgical Decision Making: A Randomized Trial. Ann Surg. 2016;264(6):889-95.

12. Chand M, Armstrong T, Britton G, Nash GF. How and why do we measure surgical risk? J R Soc Med. 2007;100(11):508-12.

13. Hammermeister KE, Henderson WG, Bronsert MR, Juarez-Colunga E, Meguid RA. Bringing Quantitative Risk Assessment Closer to the Patient and Surgeon: A Novel Approach to Improve Outcomes. Ann Surg. 2016;263(6):1039-41.

14. Meguid RA, Bronsert MR, Juarez-Colunga E, Hammermeister KE, Henderson WG. Surgical Risk Preoperative Assessment System (SURPAS): I. Parsimonious, Clinically Meaningful Groups of Postoperative Complications by Factor Analysis. Ann Surg. 2016;263(6):1042-8.

15. Meguid RA, Bronsert MR, Juarez-Colunga E, Hammermeister KE, Henderson WG. Surgical Risk Preoperative Assessment System (SURPAS): II. Parsimonious Risk Models for Postoperative Adverse Outcomes Addressing Need for Laboratory Variables and Surgeon Specialty-specific Models. Ann Surg. 2016;264(1):10-22.

16. Meguid RA, Bronsert MR, Juarez-Colunga E, Hammermeister KE, Henderson WG. Surgical Risk Preoperative Assessment System (SURPAS): III. Accurate Preoperative Prediction of 8 Adverse Outcomes Using 8 Predictor Variables. Ann Surg. 2016;264(1):23-31.

17. Henderson WG, Bronsert MR, Hammermeister KE, Lambert-Kerzner A, Meguid RA. Refining the predictive variables in the "Surgical Risk Preoperative Assessment System" (SURPAS): a descriptive analysis. Patient Saf Surg. 2019;13:28.

18. Singh AB, Bronsert MR, Henderson WG, Lambert-Kerzner A, Hammermeister KE, Meguid RA. Accurate Preoperative Prediction of Discharge Destination Using 8 Predictor Variables: A NSQIP Analysis. J Am Coll Surg. 2020;230(1):64-75 e2.

19. Rozeboom PD, Bronsert MR, Henderson WG, Velopulos CG, Colborn KL, Lambert-Kerzner A, et al. The preoperative risk tool SURPAS accurately predicts outcomes in emergency surgery. Am J Surg. 2021;222(3):643-9.

20. Henderson WG, Rozeboom PD, Bronsert MR, Colborn KL, Hammermeister KE, Lambert-Kerzner A, et al. Accuracy of the surgical risk preoperative assessment system universal risk calculator in predicting risk for patients undergoing selected operations in 9 specialty areas. Surgery. 2021;170(4):1184-94.

21. Khaneki S, Bronsert MR, Henderson WG, Yazdanfar M, Lambert-Kerzner A, Hammermeister KE, et al. Comparison of accuracy of prediction of postoperative mortality and morbidity between a new, parsimonious risk calculator (SURPAS) and the ACS Surgical Risk Calculator. Am J Surg. 2020;219(6):1065-72. 
22. Rozeboom PD, Bronsert MR, Velopulos CG, Henderson WG, Colborn KL, Hammermeister KE, et al. A comparison of the new, parsimonious tool Surgical Risk Preoperative Assessment System (SURPAS) to the American College of Surgeons (ACS) risk calculator in emergency surgery. Surgery. 2020;168(6):11529.

23. Chudgar NP, Yan S, Hsu M, Tan KS, Gray KD, Molena D, et al. Performance Comparison Between SURPAS and ACS NSQIP Surgical Risk Calculator in Pulmonary Resection. Ann Thorac Surg. 2021;111(5):1643-51.

24. Chudgar NP, Yan S, Hsu M, Tan KS, Gray KD, Nobel T, et al. External Validation of Surgical Risk Preoperative Assessment System in Pulmonary Resection. Ann Thorac Surg. 2021;112(1):228-37.

25. Leeds IL, Rosenblum AJ, Wise PE, Watkins AC, Goldblatt MI, Haut ER, et al. Eye of the beholder: Risk calculators and barriers to adoption in surgical trainees. Surgery. 2018;164(5):1117-23.

26. Barnhart BJ, Reddy SG, Arnold GK. Remind Me Again: Physician Response to Web Surveys: The Effect of Email Reminders Across 11 Opinion Survey Efforts at the American Board of Internal Medicine from 2017 to 2019. Eval Health Prof. 2021;44(3):245-59.

\section{Tables}

Table 1. Survey Participants' and Hospital Characteristics. 
Characteristics

Female

Age, mean (SD)‡

Years of practice, years, median (IQR)‡

Surgical specialty

Cardiac
General
Neurological
Other
Urologic
Vascular

Total

Affiliated

Faculty

Resident

Surgeons Surgeons

$(n=120)$

$(\mathrm{n}=21)$

$\mathrm{N}(\%)$ *

$41(34.2)$

9 (42.9)

$41.9(12.3)$

$5(1-16)$

$46.0(9.7)$

$12(3-19)$

$(n=54)$

$(n=45)$

$\mathrm{N}(\%)$ *

$\mathrm{N}(\%)^{*}$

$\mathrm{N}(\%)$ *

$14(25.9)$

49.6 (11.2)

10 (5-20)

$0(0-1)$

4 (3.3)

0 (0)

4 (7.4)

$0(0)$

84 (70.0)

17 (81.0)

$1(0.8)$

1 (4.8)

14 (11.7)

1 (4.8)

9 (7.5)

8 (6.7)

$0(0)$

$2(9.5)$

$23(42.6)$

44 (97.8)

$0(0)$

0 (0)

$13(24.1)$

$0(0)$

Education

MD

97 (80.8)

$1(0.8)$

8 (6.7)

4 (3.3)

$6(5.0)$

$3(2.5)$

1 (1.3)

MD, MHS

Hospital type

Academic hospital

94 (78.3)

$0(0)$

49 (90.7)

45 (100)

Urban community hospital

Rural hospital

Other

Bed size
$13(10.8) \quad 6(28.6) \quad 7(13.0) \quad 0(0)$ 


\begin{tabular}{lllll}
$200-399$ & $14(11.7)$ & $9(42.9)$ & $5(9.3)$ & $0(0)$ \\
\hline $400-599$ & $9(7.5)$ & $5(23.8)$ & $3(5.6)$ & $1(2.2)$ \\
\hline $600-799$ & $83(69.2)$ & $1(4.8)$ & $38(70.4)$ & $44(97.8)$ \\
\hline $800+$ & $1(0.8)$ & $0(0)$ & $1(1.9)$ & $0(0)$ \\
\hline
\end{tabular}

Abbreviations: SD, standard deviation; IQR, interquartile range; MD, Doctor of Medicine; DO, Doctor of Osteopathic Medicine; MS, Masters of Science; PhD, Doctor of Philosophy; MPH, Master of Public Health; MBA, Master of Business Administration; MHS, Master of Health Science.

*Values are frequency and column percent unless otherwise specified.

$\ddagger$ Variable contained some missing values (Age: $n=2$; Years of practice: $n=3$ ).

Table 2. Duration of Operative Risk Discussion, Source of Risk Estimates, Methods of Communicating Risk to Patients, and Communicating Risk to Referring Provider. 


\begin{tabular}{|c|c|c|c|c|}
\hline Questions & $\begin{array}{l}\text { Total } \\
(n=120) \\
N(\%)\end{array}$ & $\begin{array}{l}\text { Faculty/Affiliated } \\
\text { Surgeons } \\
\text { ( } n=75) \\
N(\%)\end{array}$ & $\begin{array}{l}\text { Resident } \\
\begin{array}{l}(n=45) \\
N(\%)\end{array}\end{array}$ & P value* \\
\hline \multicolumn{5}{|c|}{ When you discuss risk, about how much time do you spend? } \\
\hline Missing & $1(0.8)$ & $0(0)$ & $1(2.2)$ & .004 \\
\hline $1-4$ minutes & $21(17.5)$ & $7(9.3)$ & $14(31.1)$ & \\
\hline 5-9 minutes & $54(45.0)$ & $33(44.0)$ & $21(46.7)$ & \\
\hline $10-14$ minutes & $22(18.3)$ & $17(22.7)$ & $5(11.1)$ & \\
\hline$>14$ minutes & $22(18.3)$ & $18(24.0)$ & $4(8.9)$ & \\
\hline \multicolumn{5}{|l|}{ Source of risk estimates } \\
\hline \multicolumn{5}{|l|}{ Online risk calculator } \\
\hline Never $(0 \%)$ & $18(15.0)$ & $13(17.3)$ & $5(11.1)$ & .002 \\
\hline Rarely $(1-24 \%)$ & $37(30.8)$ & $25(33.3)$ & $12(26.7)$ & \\
\hline Sometimes (25-49\%) & 40 (33.3) & $17(22.7)$ & $23(51.1)$ & \\
\hline Most of the time $(50-74 \%)$ & $13(10.8)$ & $8(10.7)$ & $5(11.1)$ & \\
\hline Always $(75-100 \%)$ & $12(10.0)$ & $12(16.0)$ & $0(0)$ & \\
\hline \multicolumn{5}{|l|}{ Prior experience } \\
\hline Rarely $(1-24 \%)$ & $9(7.5)$ & $5(6.7)$ & $4(8.9)$ & $<.0001$ \\
\hline Sometimes $(25-49 \%)$ & $24(20.0)$ & $11(14.7)$ & $13(28.9)$ & \\
\hline Most of the time $(50-74 \%)$ & $41(34.2)$ & $19(25.3)$ & $22(48.9)$ & \\
\hline Always (75-100\%) & $46(38.3)$ & $40(53.3)$ & $6(13.3)$ & \\
\hline \multicolumn{5}{|l|}{ Assessment of current literature } \\
\hline Never (0\%) & $6(5.0)$ & $5(6.7)$ & $1(2.2)$ & .004 \\
\hline Rarely (1-24\%) & $8(6.7)$ & $2(2.7)$ & $6(13.3)$ & \\
\hline Sometimes (25-49\%) & $34(28.3)$ & $16(21.3)$ & $18(40.0)$ & \\
\hline Most of the time $(50-74 \%)$ & $42(35.0)$ & $27(36.0)$ & $15(33.3)$ & \\
\hline Always $(75-100 \%)$ & $30(25.0)$ & $25(33.3)$ & $5(11.1)$ & \\
\hline \multicolumn{5}{|l|}{ Other sources } \\
\hline Missing & $11(9.2)$ & $0(0)$ & $11(24.4)$ & $<.0001$ \\
\hline Never $(0 \%)$ & $79(65.8)$ & $54(72.0)$ & $25(55.6)$ & \\
\hline Rarely $(1-24 \%)$ & $12(10.0)$ & $9(12.0)$ & $3(6.7)$ & \\
\hline Sometimes (25-49\%) & $7(5.8)$ & $3(4.0)$ & $4(8.9)$ & \\
\hline Most of the time $(50-74 \%)$ & $5(4.2)$ & $4(5.3)$ & $1(2.2)$ & \\
\hline
\end{tabular}


Always (75-100\%)

$6(5.0)$

$5(6.7)$

$1(2.2)$

Methods of communicating risk to patients

Pre-anesthesia clinic

Missing

Never (0\%)

Rarely (1-24\%)

Sometimes (25-49\%)

Most of the time (50-74\%)

Always (75-100\%)

$1(0.8)$

$6(5.0)$

$13(10.8)$

38 (31.7)

46 (38.3)

$16(13.3)$

Face to face communication

Never $0(0)$

Rarely (1-24\%)

Sometimes (25-49\%)

Most of the time (50-74\%)

Always (75-100\%)

Phone call

Never (0\%)

Rarely (1-24\%)

Sometimes (25-49\%)

Most of the time (50-74\%)

Always (75-100\%)

Rely on resident to communicate risk

Missing

Never (0\%)

Rarely (1-24\%)

Sometimes (25-49\%)

Most of the time (50-74\%)

Always (75-100\%)

Rely on advance practice provider

Never (0\%)

Rarely (1-24\%)

Sometimes (25-49\%)

Most of the time (50-74\%)

Always

3 (2.5)

9 (7.5)

25 (20.8)

$83(69.2)$

40 (33.3)

56 (46.7)

19 (15.8)

$4(3.3)$

$1(0.8)$

$1(0.8)$

47 (39.2)

34 (28.3)

15 (12.5)

$12(10.0)$

$11(9.2)$

53 (44.2)

$36(30.0)$

26 (21.7)

$5(4.2)$

$0(0)$
$0(0) \quad 1(2.2)$

$4(5.3) \quad 2(4.4)$

$9(12.0) \quad 4(8.9)$

$19(25.3) \quad 19(42.2)$

$28(37.3) \quad 18(40.0)$

$15(20.0) \quad 1(2.2)$

.02

43

\begin{tabular}{rr}
$1(1.3)$ & $2(4.4)$ \\
$4(5.3)$ & $5(11.1)$ \\
$16(21.3)$ & $9(20.0)$ \\
$54(72.0)$ & $29(64.4)$ \\
\hline
\end{tabular}

$23(30.7) \quad 17(37.8) \quad .74$

$38(50.7) \quad 18(40.0)$

$11(14.7) \quad 8(17.8)$

$2(2.7) \quad 2(4.4)$

$1(1.3) \quad 0(0)$

$0(0) \quad 1(2.2) \quad<.0001$

$34(45.3) \quad 13(28.9)$

$30(40.0) \quad 4(8.9)$

$9(12.0) \quad 6(13.3)$

$2(2.7) \quad 10(22.2)$

$0(0) \quad 11(24.4)$

$35(46.7) \quad 18(40.0) \quad .61$

$23(30.7) \quad 13(28.9)$

$15(20.0) \quad 11(24.4)$

$2(2.7) \quad 3(6.7)$

$0(0) \quad 0(0)$ 


\begin{tabular}{lrrrr}
\hline Handout/pamphlet & & & & \\
$\quad$ Never (0\%) & $40(33.3)$ & $28(37.3)$ & $12(26.7)$ & $<.0001$ \\
Rarely (1-24\%) & $34(28.3)$ & $11(14.7)$ & $23(51.1)$ & \\
Sometimes (25-49\%) & $23(19.2)$ & $15(20.0)$ & $8(17.8)$ & \\
Most of the time (50-74\%) & $14(11.7)$ & $12(16.0)$ & $2(4.4)$ & \\
Always (75-100\%) & $9(7.5)$ & $9(12.0)$ & $0(0)$ & \\
\hline Class/video & & & & \\
Never (0\%) & $86(71.7)$ & $58(77.3)$ & $28(62.2)$ & .15 \\
Rarely (1-24\%) & $22(18.3)$ & $9(12.0)$ & $13(28.9)$ & \\
Sometimes (25-49\%) & $7(5.8)$ & $4(5.3)$ & $3(6.7)$ & \\
Most of the time (50-74\%) & $1(0.8)$ & $1(1.33)$ & $0(0)$ & \\
Always (75-100\%) & $4(3.3)$ & $3(4.0)$ & $1(2.2)$ & \\
\hline How often do you or your team communicate patient risk to their referring provider? & & \\
\hline Missing & $1(0.8)$ & $0(0)$ & $1(2.2)$ & $<.001$ \\
Never (0\%) & $12(10.0)$ & $2(2.7)$ & $10(22.2)$ & \\
Rarely (1-24\%) & $45(37.5)$ & $25(33.3)$ & $20(44.4)$ & \\
Sometimes (25-49\%) & $37(30.8)$ & $26(34.7)$ & $11(24.4)$ & \\
Most of the time (50-74\%) & $16(13.3)$ & $8(18.7)$ & $2(4.4)$ & \\
Always (75-100\%) & $9(7.5)$ & & & \\
\hline
\end{tabular}

*P values are from Fischer's exact test.

Table 3. Factors Related to Likelihood of Using Risk Assessment Tool.

\begin{tabular}{lllll} 
& Total & Faculty & Resident & \\
\cline { 2 - 5 } & $(\mathrm{n}=120)$ & $(\mathrm{n}=75)$ & $(\mathrm{n}=45)$ & \\
\cline { 2 - 5 } & $\mathrm{N}(\%)$ & $\mathrm{N}(\%)$ & $\mathrm{N}(\%)$ & P value* $^{*}$ \\
\hline Patient age $>$ 65 years & $92(76.7)$ & $56(74.7)$ & $36(80.0)$ & .66 \\
\hline Patient asks about risk & $83(69.2)$ & $48(64.0)$ & $35(77.8)$ & .15 \\
\hline Patient has significant risk factors & $108(90.0)$ & $67(89.3)$ & $41(91.1)$ & .99 \\
\hline To dissuade patient/family from surgery & $84(70.0)$ & $54(72.0)$ & $30(66.7)$ & .54 \\
\hline Emergent operation & $59(49.2)$ & $42(56.0)$ & $17(37.8)$ & .06
\end{tabular}

*P values are from Fischer's exact test.

Table 4. Potential Barriers to Use of Risk Assessment Tool and Features that Make Risk Assessment Tool Useful. 
Question

$\begin{array}{llll}\text { Total } & \text { Faculty } & \text { Resident } & \\ (n=120) & (n=75) & (n=45) & \\ N(\%) & N(\%) & N(\%) & \begin{array}{l}P \\ \text { value }\end{array}\end{array}$

\section{Potential Barriers to use of risk calculator}

The amount of time it takes to use

\begin{tabular}{|c|c|c|c|}
\hline Not a barrier & $8(6.7)$ & $7(9.3)$ & $1(2.2)$ \\
\hline A small barrier & $\begin{array}{l}33 \\
(27.5)\end{array}$ & $\begin{array}{l}25 \\
(33.3)\end{array}$ & $8(17.8)$ \\
\hline A moderate barrier & $\begin{array}{l}47 \\
(39.2)\end{array}$ & $\begin{array}{l}25 \\
(33.3)\end{array}$ & $\begin{array}{l}22 \\
(48.9)\end{array}$ \\
\hline A significant barrier & $\begin{array}{l}32 \\
(26.7)\end{array}$ & $\begin{array}{l}18 \\
(24.0)\end{array}$ & $\begin{array}{l}14 \\
(31.1)\end{array}$ \\
\hline
\end{tabular}

The risk calculator not being integrated with the EHR

\begin{tabular}{llll} 
Not a barrier & 13 & 12 & $1(2.2)$ \\
& $(10.8)$ & $(16.0)$ & \\
A small barrier & 33 & 21 & 12 \\
& $(27.5)$ & $(28.0)$ & $(26.7)$ \\
A moderate barrier & 39 & 21 & 18 \\
& $(32.5)$ & $(28.0)$ & $(40.0)$ \\
\hline A significant barrier & 35 & 21 & 14 \\
& $(29.2)$ & $(28.0)$ & $(31.1)$
\end{tabular}

The inability of patients to understand the results

\begin{tabular}{llll} 
Not a barrier & $\begin{array}{l}16 \\
(13.3)\end{array}$ & $\begin{array}{l}11 \\
(14.7)\end{array}$ & $5(11.1)$ \\
A small barrier & 48 & 29 & .96 \\
& $(40.0)$ & $(38.7)$ & $(42.2)$ \\
\hline A moderate barrier & 32 & 20 & 12 \\
& $(26.7)$ & $(16.7)$ & $(26.7)$ \\
\hline A significant barrier & 24 & 15 & $9(20.0)$
\end{tabular}

The inaccessibility of risk tool during patient visit

$\begin{array}{lllll}\text { Missing } & 1(0.8) & 0(0) & 1(2.2) & .02 \\ \text { Not a barrier } & 13 & 12 & 1(2.2) & \\ & (10.8) & (16.0) & & \end{array}$




\begin{tabular}{llll} 
A small barrier & 32 & 21 & 11 \\
& $(26.7)$ & $(28.0)$ & $(24.4)$ \\
\hline A moderate barrier & 42 & 20 & 22 \\
& $(35.0)$ & $(26.7)$ & $(48.9)$ \\
\hline A significant barrier & 32 & 22 & 10 \\
& $(26.7)$ & $(29.3)$ & $(22.2)$
\end{tabular}

Trust of the risk tool accuracy

$\begin{array}{lllll}\text { Not a barrier } & 17 & 12 & 5(11.1) & .16 \\ & (14.2) & (16.0) & & \\ \text { A small barrier } & 32 & 19 & 13 \\ & (26.7) & (25.3) & (28.9) \\ \text { A moderate barrier } & 44 & 23 & 21 \\ & (36.7) & (30.7) & (46.7) \\ \text { A significant barrier } & 27 & 21 & 6(13.3)\end{array}$

Native language of patient

$\begin{array}{llll}\text { Not a barrier } & 32 & 26 & 6(13.3) \\ & (26.7) & (34.7) & \\ \text { A small barrier } & 49 & 29 & 20 \\ & (40.8) & (38.7) & (44.4) \\ \text { A moderate barrier } & 26 & 10 & 16 \\ & (21.7) & (13.3) & (35.6) \\ \text { A significant barrier } & 13 & 10 & 3(6.7) \\ & (10.8) & (13.3) & \end{array}$

\section{Potential Features that make risk calculator useful}

Prediction of good surgical outcome

\begin{tabular}{|c|c|c|c|c|}
\hline \multicolumn{5}{|c|}{ tion of good surgical outcome } \\
\hline Not useful at all & $3(2.5)$ & $2(2.7)$ & $1(2.2)$ & .53 \\
\hline Somewhat useful & $\begin{array}{l}23 \\
(19.2)\end{array}$ & $\begin{array}{l}16 \\
(21.3)\end{array}$ & $7(15.6)$ & \\
\hline Very useful & $\begin{array}{l}41 \\
(34.2)\end{array}$ & $\begin{array}{l}28 \\
(37.3)\end{array}$ & $\begin{array}{l}13 \\
(28.9)\end{array}$ & \\
\hline Extremely useful & $\begin{array}{l}49 \\
(40.8)\end{array}$ & $\begin{array}{l}26 \\
(34.7)\end{array}$ & $\begin{array}{l}23 \\
(51.1)\end{array}$ & \\
\hline Don't know & $4(3.3)$ & $3(4.0)$ & $1(2.2)$ & \\
\hline
\end{tabular}

Prediction of minor complications

Not useful at all

Somewhat useful ations

9 (7.5)

$6(8.0)$

$3(6.7)$

.12
37

14 
(42.5) (49.3) (31.1)

Very useful

\begin{tabular}{|c|c|c|}
\hline $\begin{array}{l}36 \\
(30.0)\end{array}$ & $\begin{array}{l}22 \\
(29.3)\end{array}$ & $\begin{array}{l}14 \\
(31.1)\end{array}$ \\
\hline $\begin{array}{l}22 \\
(18.3)\end{array}$ & $9(12.0)$ & $\begin{array}{l}13 \\
(28.9)\end{array}$ \\
\hline $2(1.7)$ & $1(1.3)$ & $1(2.2)$ \\
\hline
\end{tabular}

Prediction of major complications

\begin{tabular}{llll} 
Not useful at all & $1(0.8)$ & $1(1.3)$ & $0(0)$ \\
\hline Somewhat useful & $5(4.2)$ & $4(5.3)$ & $1(2.2)$ \\
\hline Very useful & 34 & 21 & 13 \\
& $(28.3)$ & $(28.0)$ & $(28.9)$ \\
Extremely useful & 78 & 48 & 30 \\
& $(65.0)$ & $(64.0)$ & $(66.7)$ \\
Don't know & $2(1.7)$ & $1(1.3)$ & $1(2.2)$
\end{tabular}

Prediction of mortality

\begin{tabular}{|c|c|c|c|}
\hline Not useful at all & $1(0.8)$ & $1(1.3)$ & $0(0)$ \\
\hline Somewhat useful & $6(5.0)$ & $5(6.7)$ & $1(2.2)$ \\
\hline Very useful & $\begin{array}{l}27 \\
(22.5)\end{array}$ & $\begin{array}{l}16 \\
(21.3)\end{array}$ & $\begin{array}{l}11 \\
(24.4)\end{array}$ \\
\hline Extremely useful & $\begin{array}{l}85 \\
(70.8)\end{array}$ & $\begin{array}{l}53 \\
(70.7)\end{array}$ & $\begin{array}{l}32 \\
(71.1)\end{array}$ \\
\hline Don't know & $1(0.8)$ & $0(0)$ & $1(2.2)$ \\
\hline
\end{tabular}

Automatic integration of risk factors from the EHR

\begin{tabular}{|c|c|c|c|}
\hline Not useful at all & $4(3.3)$ & $4(5.3)$ & $0(0)$ \\
\hline Somewhat useful & $\begin{array}{l}18 \\
(15.0)\end{array}$ & $\begin{array}{l}14 \\
(18.7)\end{array}$ & $4(8.9)$ \\
\hline Very useful & $\begin{array}{l}26 \\
(21.7)\end{array}$ & $\begin{array}{l}16 \\
(21.3)\end{array}$ & $\begin{array}{l}10 \\
(22.2)\end{array}$ \\
\hline Extremely useful & $\begin{array}{l}71 \\
(59.2)\end{array}$ & $\begin{array}{l}41 \\
(54.7)\end{array}$ & $\begin{array}{l}30 \\
(66.7)\end{array}$ \\
\hline Don't know & $1(0.8)$ & $0(0)$ & $1(2.2)$ \\
\hline
\end{tabular}

Automatic recording of results into the EHR

Not useful at all

Somewhat useful

$\begin{array}{llll}5(4.2) & 5(6.7) & 0(0) & .20 \\ 18 & 13 & 5(11.1) & \\ (15.0) & (17.3) & & \end{array}$




\begin{tabular}{|c|c|c|c|c|}
\hline Very useful & $\begin{array}{l}30 \\
(25.0)\end{array}$ & $\begin{array}{l}20 \\
(26.7)\end{array}$ & $\begin{array}{l}10 \\
(22.2)\end{array}$ & \\
\hline Extremely useful & $\begin{array}{l}63 \\
(52.5)\end{array}$ & $\begin{array}{l}34 \\
(45.3)\end{array}$ & $\begin{array}{l}29 \\
(64.4)\end{array}$ & \\
\hline Don't know & $4(3.3)$ & $3(4.0)$ & $1(2.2)$ & \\
\hline \multicolumn{5}{|c|}{ Prediction of post-surgery infection } \\
\hline Not useful at all & $2(1.7)$ & $2(2.7)$ & $0(0)$ & .11 \\
\hline Somewhat useful & $\begin{array}{l}21 \\
(17.5)\end{array}$ & $\begin{array}{l}17 \\
(22.7)\end{array}$ & $4(8.9)$ & \\
\hline Very useful & $\begin{array}{l}49 \\
(40.8)\end{array}$ & $\begin{array}{l}30 \\
(40.0)\end{array}$ & $\begin{array}{l}19 \\
(42.2)\end{array}$ & \\
\hline Extremely useful & $\begin{array}{l}47 \\
(39.2)\end{array}$ & $\begin{array}{l}26 \\
(34.7)\end{array}$ & $\begin{array}{l}21 \\
(46.7)\end{array}$ & \\
\hline Don't know & $1(0.8)$ & $0(0)$ & $1(2.2)$ & \\
\hline
\end{tabular}

Abbreviation: EHR, electronic health record.

*P values are from Fischer's exact test.

\section{Supplementary Files}

This is a list of supplementary files associated with this preprint. Click to download.

- 20211112RiskAssessmentToolAttitudesAppendix1.docx 